University of Nebraska - Lincoln

DigitalCommons@University of Nebraska - Lincoln

$9-19-2006$

\title{
In-cluster-structured exchange-coupled magnets with high energy densities
}

\author{
X. Rui \\ University of Nebraska - Lincoln \\ Jeffrey E. Shield \\ University of Nebraska - Lincoln, jshield@unl.edu \\ Zhiguang Sun \\ University of Nebraska - Lincoln, zsun3@unl.edu \\ Yinfan Xu \\ University of Nebraska - Lincoln, yxu2@unl.edu \\ David J. Sellmyer \\ University of Nebraska-Lincoln, dsellmyer@unl.edu
}

Follow this and additional works at: https://digitalcommons.unl.edu/physicssellmyer

Part of the Physics Commons

Rui, X.; Shield, Jeffrey E.; Sun, Zhiguang; Xu, Yinfan; and Sellmyer, David J., "In-cluster-structured exchange-coupled magnets with high energy densities" (2006). David Sellmyer Publications. 195. https://digitalcommons.unl.edu/physicssellmyer/195

This Article is brought to you for free and open access by the Research Papers in Physics and Astronomy at DigitalCommons@University of Nebraska - Lincoln. It has been accepted for inclusion in David Sellmyer Publications by an authorized administrator of DigitalCommons@University of Nebraska - Lincoln. 


\title{
In-cluster-structured exchange-coupled magnets with high energy densities
}

\author{
X. Rui and J. E. Shield ${ }^{\text {a) }}$ \\ Department of Mechanical Engineering, University of Nebraska-Lincoln, Lincoln, Nebraska 68588 and \\ Nebraska Center for Materials and Nanoscience, University of Nebraska-Lincoln, Lincoln, Nebraska 68588 \\ Z. Sun, Y. Xu, and D. J. Sellmyer \\ Department of Physics and Astronomy, University of Nebraska-Lincoln, Lincoln, Nebraska 68588 and \\ Nebraska Center for Materials and Nanoscience, University of Nebraska-Lincoln, Lincoln, Nebraska 68588
}

(Received 5 June 2006; accepted 27 July 2006; published online 19 September 2006)

\begin{abstract}
In this letter, the authors demonstrate isotropic Fe-Pt exchange-spring nanocomposite permanent magnets with a soft magnetic phase fraction of greater than 0.5 with a coercivity of $6.5 \mathrm{kOe}$, single-phase-like magnetic behavior, and an energy product of 25.1 MG Oe. Sub-10-nm Fe-Pt clusters are formed with compositions in the two-phase $\mathrm{Fe}_{3} \mathrm{Pt}$ and $\mathrm{FePt}$ regions. Intracluster structuring on a scale of a few nanometers occurs after appropriate heat treatment. This ensures full exchange coupling between the two phases, allowing greater soft magnetic phase fractions. The results provide insight into developing high energy product nanostructured permanent magnets. (c) 2006 American Institute of Physics. [DOI: 10.1063/1.2355448]
\end{abstract}

Exchange-spring nanocomposite magnets ${ }^{1,2}$ captured the attention of the permanent magnet community by providing hopes of very high energy densities. ${ }^{3,4}$ These materials combine soft and hard magnetic phases of nanoscale dimensions. Because of magnetic interactions across grain boundaries or interfaces, the magnetic moments of one grain influence the magnetic moments in a neighboring grain ("exchange coupling"). The extent of the exchange coupling is governed by the exchange length, which is approximately twice the domain wall width of the hard magnetic phase or on the order of $<10 \mathrm{~nm}^{5}$ If the dimension of the soft magnetic phase exceeds the exchange length, then some of the soft magnetic phase remains uncoupled and can be easily rotated with an applied external field, resulting in a loss in coercivity. The exchange coupling produces a very high remanent magnetization because the soft phase remains aligned with the neighboring hard magnetic grains, resulting in high energy densities, especially compared to single-phase materials. However, energy densities achieved thus far have been far less than projected. ${ }^{3,4}$ This is primarily the result of a loss of coercive force caused in part by the exchange interactions themselves and in part by uncoupled portions of the soft magnetic phase. The strong exchange interactions lead to the development of interaction domains and magnetic reversal by domain expansion. ${ }^{6}$ Uncoupled soft magnetic regions act as initiation sites for magnetic reversal. ${ }^{7}$ For complete coupling, the dimension of the soft phase must be on the order of twice the domain wall width of the hard magnet phase (typically less than $10 \mathrm{~nm}$ ). Nearly ideal exchange coupling between soft and hard magnetic phases has been effectively realized by controlling the dimension of the soft magnetic phase through the fabrication of soft magnetic nanoparticles below $10 \mathrm{~nm}$ using chemical self-assembly ${ }^{8}$ and gas aggregation ${ }^{9}$ approaches. Both approaches resulted in energy products above $20 \mathrm{MG} \mathrm{Oe}$ in $\mathrm{Fe}-\mathrm{Pt}$ nanocomposites, more than $50 \%$ greater than expected for isotropic, single-phase noninteracting FePt. However, the amount of soft phase fraction was limited in both cases, which significantly constrains the potential energy product.

\footnotetext{
a) Author to whom correspondence should be addressed; FAX: 402/4721465; electronic mail: jshield2@unl.edu
}

In this letter, we report the fabrication of two-phase $\mathrm{Fe}_{3} \mathrm{Pt} / \mathrm{FePt}$ nanoparticles that confine both the hard and soft magnetic phases within individual nanometer-scale clusters. The clusters are isolated from each other in a nonmagnetic matrix, which effectively eliminates interparticle magnetic interactions. This approach overcomes two significant difficulties associated with exchange-spring permanent magnets. Firstly, it ensures that the dimension of the $\mathrm{Fe}_{3} \mathrm{Pt}$ soft magnetic phase is below the critical size for complete coupling $(\leqslant 10 \mathrm{~nm})$. With complete coupling, the nanocomposite will maximize the benefits of the exchange interactions, and magnetic reversal will occur simultaneously for both the hard and soft magnetic phases. Secondly, magnetically isolating the particles ensures that each nanoparticle magnetically reverses independently from other nanoparticles, eliminating the coupled demagnetization that significantly reduces coercivity. ${ }^{6}$ The high energy product achieved here is a proof-ofconcept approach in designing nanostructured permanent magnets, and shows that early projections of ultrahigh energy products that have thus far been unrealized may be achievable.

Fe-Pt alloy clusters with compositions within the twophase $\mathrm{Fe}_{3} \mathrm{Pt}-\mathrm{FePt}$ region were produced by inert gas condensation in a high-pressure $\mathrm{Ar} / \mathrm{He}$ dc magnetron sputtering chamber. ${ }^{10-12}$ By alternately depositing clusters and nonmagnetic $\mathrm{SiO}_{2}$ or $\mathrm{C}$ from a second rf sputtering gun onto a $\mathrm{Si}$ substrate, the Fe-Pt clusters were effectively isolated from each other to minimize magnetostatic interactions. The composition of the clusters was determined by energy dispersive $\mathrm{x}$-ray spectroscopy (EDS) in the transmission electron microscope on clusters deposited directly onto carbon support grids. A nonconverged electron beam was used during EDS analysis so that the composition determined by EDS represented an average composition of many clusters. Compositions determined in this way matched expected trends in the saturation magnetization as a function of Fe content. Control clusters with compositions in the single-phase $\mathrm{Fe}_{3} \mathrm{Pt}$ and FePt regions were also produced. Deposition rates were measured in situ using a quartz crystal thickness monitor. The deposition rates were cross-checked ex situ using transmission electron microscopy by determining the number of clusters deposited per unit area per time. Deposition rates were 


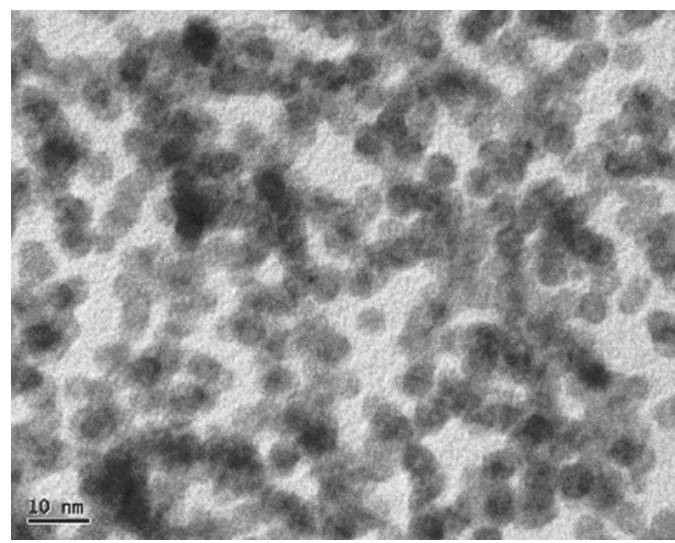

FIG. 1. Transmission electron micrograph of Fe-Pt alloy clusters produced by gas aggregation. The average size is $6 \mathrm{~nm}$.

consistent between the two measuring methods. Thus, the mass of magnetic material (clusters) deposited was determined. Normalizing the magnetic data to the mass of clusters resulted in magnetization values that fit within expected trends with respect to composition, again suggesting that our determination of deposition rates was accurate. The samples were heat treated using rapid thermal annealing in an $\mathrm{Ar}$ atmosphere. Characterization was completed by transmission electron microscopy (TEM) using a JEOL2010 operating at $200 \mathrm{kV}$, and samples were made by depositing clusters directly onto a carbon support membrane. Characterization was also done using x-ray diffraction using $\mathrm{Cu} K \alpha$ radiation with a Rigaku $\theta-\theta$ diffractometer, and magnetic properties were measured by superconducting quantum interference device magnetometry at room temperature using a Quantum Design magnetic property measurement system. The X-ray data were refined using SIROQUANT, a Rietveld refinement software package.

TEM revealed that the as-deposited clusters were approximately $6 \mathrm{~nm}$ in diameter (Fig. 1). The deposition conditions led to some particle-particle contact, but the clusters are largely isolated. The as-deposited Fe-Pt clusters formed in the Fe-Pt solid-solution face-centered-cubic structure (A1). Thus, heat treatment was required to form the $\mathrm{Fe}_{3} \mathrm{Pt}$ $L 1_{2}$ and FePt $L 1_{0}$ structures. The heat treatments used in this study were multistage, starting at $580{ }^{\circ} \mathrm{C}$ for $10 \mathrm{~min}$, then $550{ }^{\circ} \mathrm{C}$ for $30 \mathrm{~min}$, and finally $600{ }^{\circ} \mathrm{C}$ for 10 and $20 \mathrm{~min}$. $\mathrm{X}$-ray diffraction data revealed the presence of both the ordered $\mathrm{Fe}_{3} \mathrm{Pt}$ and FePt phases at the completion of the heat treatment process for compositions in the two-phase region, while compositions in the single-phase FePt region consisted of only the $L 1_{0}$ structure (Fig. 2). The two phases are best identified in the two-theta region around the $\{002\}$ diffraction peaks. The tetragonal distortion accompanying the formation of the $L 1_{0}$ structure results in the splitting of the $\{002\}$ diffraction peak into $\{200\}$ and (002) components. The $\{002\}$ diffraction peak from the ordered $\mathrm{Fe}_{3} \mathrm{Pt}$ structure lies between (200) and (002) $L 1_{0}$ diffraction peaks. Excellent agreement between the experimental and calculated diffraction patterns was observed if both ordered $\mathrm{Fe}_{3} \mathrm{Pt}$ and $\mathrm{FePt}$ structures were included [Figs. 2(a) and 2(b)]; when a pattern was calculated considering only the FePt structure, an obvious peak was observed in the difference pattern, which coincided with the $\{200\}$ peak of the ordered $\mathrm{Fe}_{3} \mathrm{Pt}$ structure [Fig. 2(c)]. The diffraction data from clusters in the singlephase FePt composition region showed excellent agreement Downloaded 30 Mar 2007 to 129.93.16.206. Redistribution subject

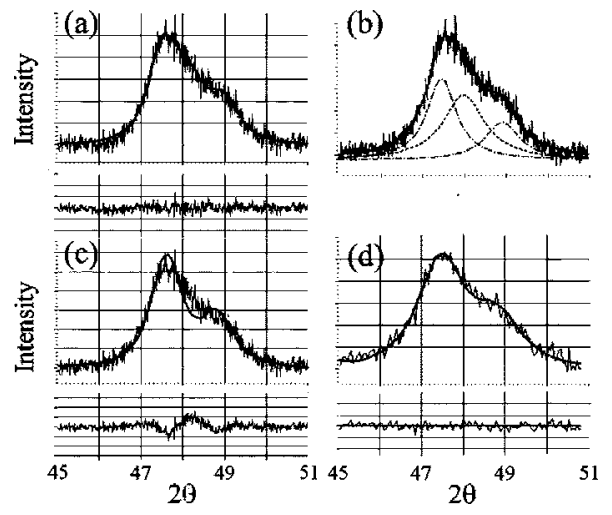

FIG. 2. (a) X-ray diffraction scan of the two-phase Fe-Pt alloy clusters and the Rietveld fit (solid line) using both FePt and ordered $\mathrm{Fe}_{3} \mathrm{Pt}$. The line below the scan is the difference pattern between the experimental data and Rietveld calculation. (b) X-ray diffraction data showing the $\{200\}$ and (002) FePt diffraction peaks $(----\ldots--)$ and the $\{002\} \mathrm{Fe}_{3} \mathrm{Pt}$ diffraction peak (-----). (c) X-ray diffraction scan of the two-phase Fe-Pt alloy clusters and the Rietveld fit (solid line) using only the FePt phase. Note the emergence of a peak in the difference pattern, which corresponds to the $\{002\}$ $\mathrm{Fe}_{3} \mathrm{Pt}$ peak. (d) X-ray diffraction scan of single-phase FePt clusters and the Rietveld fit (solid line) using only the FePt phase.

with the calculated data when considering only the FePt phase [Fig. 2(d)]. X-ray diffraction also allows a quantifiable measure of the volume fraction of phases present in a material; ${ }^{13}$ here, it was determined that the clusters contained 55 vol $\%$ of the ordered $\mathrm{Fe}_{3} \mathrm{Pt}$ phase at a composition of 33 at. \% Pt. Thermal magnetic analysis also corroborated the two-phase nature by revealing the Curie temperatures for both ordered $\mathrm{Fe}_{3} \mathrm{Pt}$ and FePt.

The nanostructure of the heat-treated clusters was investigated using TEM (Fig. 3). While some coalescence has occurred, the clusters remained largely isolated, limiting the magnetostatic interactions. The clusters also display internal contrast that is a characteristic of a number of structural features such as twins and antiphase boundaries, both of which are likely in these materials given the ordering transformation. Because of the similarities in the crystal structures and the scale of the structure, it is difficult to distinguish between the ordered $\mathrm{Fe}_{3} \mathrm{Pt}$ and $\mathrm{FePt}$ phases. Li et al. ${ }^{14}$ used high resolution electron microscopy to distinguish $\mathrm{Fe}_{3} \mathrm{Pt}$ and $\mathrm{FePt}$. Also notable in their study was that the contrast between the two phases was not sharp. In Fig. 3, there are regions with mottled contrast on a scale of $1-3 \mathrm{~nm}$ that are similar in nature to the phase boundaries observed in Ref. 14. High resolution electron microscopy is necessary to more clearly

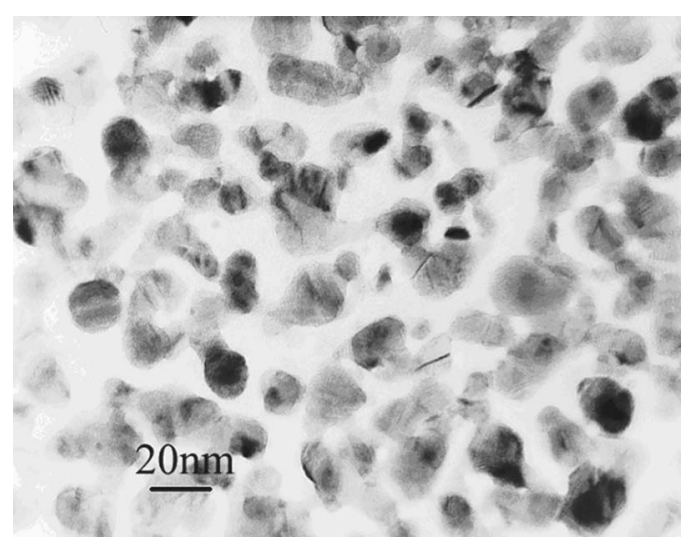

FIG. 3. Transmission electron micrograph of heat-treated Fe-Pt clusters with a composition $\left(\mathrm{Fe}_{67} \mathrm{Pt}_{33}\right)$ within the two-phase region.

AIP license or copyright, see http://apl.aip.org/apl/copyright.jsp 


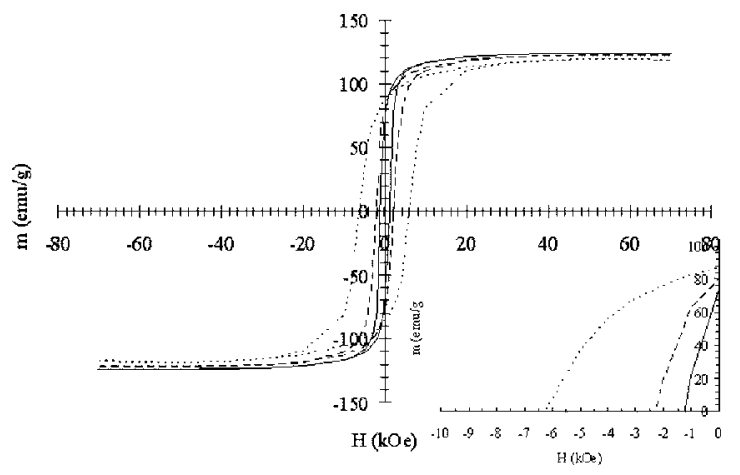

FIG. 4. Hysteresis measurements for two-phase Fe-Pt clusters after different heat treatments showing the development of coercivity. The solid line corresponds to the $580^{\circ} \mathrm{C} / 10 \mathrm{~min}$ heat treatment, the dashed line after the additional heat treatment at $550{ }^{\circ} \mathrm{C}$ for $30 \mathrm{~min}$, and the dotted line after the final heat treatment at $600{ }^{\circ} \mathrm{C}$ for $20 \mathrm{~min}$.

determine the phase separation in our samples. However, given the strong magnetic exchange coupling observed in our samples (see below), it is most likely that the clusters are internally phase separated.

The development of coercivity differed greatly between the single-phase and two-phase Fe-Pt clusters. The singlephase FePt clusters rapidly transformed to the hard magnetic $L 1_{0}$ structure, resulting in a high coercivity of $10 \mathrm{kOe}$ after heat treatment at $580{ }^{\circ} \mathrm{C}$ for $10 \mathrm{~min}$, which did not change with subsequent heat treatment. However, the coercivity of the two-phase clusters was less than $2 \mathrm{kOe}$ after the initial heat treatment. Additional heat treatments, however, resulted in significant improvement in the coercivity of the two-phase clusters, which reached a maximum of $6.5 \mathrm{kOe}$, extraordinarily high for a structure containing more than 50\% soft magnetic phase (Fig. 4). The development of coercivity in the two-phase clusters requires phase separation with (relatively) long diffusion distances, especially compared to the ordering process, and thus more extensive heat treatments were required to induce this phase separation. An analysis of the diffusion profile ${ }^{15}$ reveals diffusion lengths of $\sim 3 \mathrm{~nm}$ at $600{ }^{\circ} \mathrm{C}$ for $10 \mathrm{~min}$, reasonably consistent with the scale of the features observed by TEM in heat-treated clusters.

The hysteresis measurements of the two-phase clusters show that the magnetization changes uniformly in the second quadrant, reminiscent of a single-phase material (Fig. 5). This indicates that there is effective exchange coupling between the hard and soft phases within each cluster. In addition, the remanence ratio, $M_{r} / M_{s}$, of 0.7 is well above 0.5 , the value expected for isotropic, noninteracting structures given by the Stoner-Wohlfarth model. ${ }^{16}$ Note that the increased remanence is not due to crystallographic texture, as

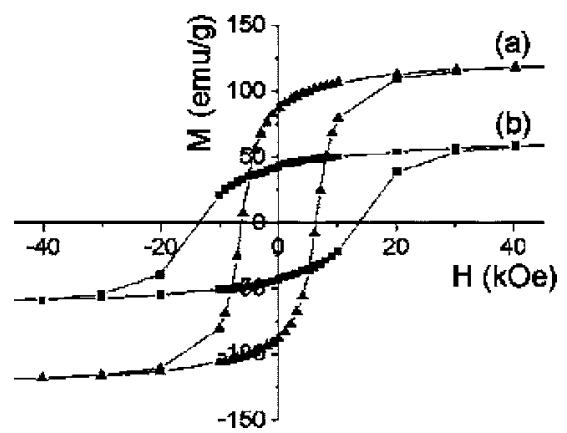

FIG. 5. Hysteresis measurements for optimally heat-treated (a) two-phase $\mathrm{Fe}-\mathrm{Pt}$ clusters and (b) single-phase FePt clusters. 240, 599 (1948).
De-Pt clusters and (b) single-phase FePt clusters. the x-ray diffraction peak intensity of the $\{200\} \mathrm{FePt}$ peaks was twice that of the (002) of FePt, as expected. Conversely, the remanence ratio of the single-phase FePt clusters was 0.5 , revealing that these represent noninteracting particles according to the Stoner-Wohlfarth model.

The maximum energy product after optimum annealing of the two-phase clusters reached 25.1 MG Oe at 33.1 at. \% Pt. This is more than twice that achieved for the single-phase FePt (11.8 MG Oe), and more than 25\% higher than that reported previously for $\mathrm{Fe}_{3} \mathrm{Pt} / \mathrm{FePt}$ (20.1 MG Oe) (Ref. 7) and $\mathrm{Fe} / \mathrm{FePt}$ (20.7 MG Oe) (Ref. 8) nanocomposites. The energy product of the single-phase FePt clusters was reasonably close to the theoretical value of $12.4 \mathrm{MG}$ Oe for isolated, noninteracting magnetic particles. This shows that our technique for estimating cluster mass is reasonable, and may in fact slightly overestimate the amount of clusters in a given sample. As a result, the energy products reported here are reasonable and on the conservative side.

In summary, the fabrication of two-phase clusters that display intracluster exchange coupling and excellent magnetic properties has been demonstrated. After appropriate heat treatment, magnetic measurements suggested that phase separation to form a mixture of soft magnetic ordered $\mathrm{Fe}_{3} \mathrm{Pt}$ and hard magnetic FePt occurred within individual clusters. The magnetic measurements revealed effective exchange coupling, high remanence ratios, a coercivity of $6.5 \mathrm{kOe}$, and energy product of $25.1 \mathrm{MGOe}$. The high soft magnetic phase fraction and energy product are both significantly higher than previously achieved. Our approach provides insights into how the early projections of very high energy products for exchange-spring permanent magnets can be realized. The key will be to construct materials and systems that have nanoscale features to ensure effective exchange coupling but that have particles or grains that reverse independently of one another.

This work was supported by the National Science Foundation through the Materials Science and Engineering Center QSPINS at the University of Nebraska.

${ }^{1}$ E. F. Kneller and R. Hawig, IEEE Trans. Magn. 27, 3588 (1991).

${ }^{2}$ D. J. Sellmyer, Nature (London) 420, 374 (2002).

${ }^{3}$ R. Skomski and J. M. D. Coey, Phys. Rev. B 48, 15812 (1993).

${ }^{4}$ R. Fischer, T. Schrefl, H. Kronmuller, and J. Fidler, J. Magn. Magn. Mater. 150, 329 (1995).

${ }^{5}$ R. Skomski, J. Phys.: Condens. Matter 15, R841 (2003).

${ }^{6}$ J. E. Shield, J. Zhou, S. Aich, V. Ravindran, R. Skomski, and D. J. Sellmyer, J. Appl. Phys. 99, 08B508 (2006).

${ }^{7}$ Y. Gao, D. Shindo, and A. K. Petford-Long, J. Appl. Phys. 93, 8119 (2003).

${ }^{8}$ H. Zeng, J. Li, J. P. Liu, Z. L. Wang, and S. Sun, Nature (London) 420, 395 (2002).

${ }^{9}$ X. Rui, Y. Xu, Z. Sun, D. J. Sellmyer, Z. Liu, D. J. Miller, and J. E. Shield, J. Magn. Magn. Mater. 305, 76 (2006).

${ }^{10}$ H. Haberland, M. Karrais, M. Mall, and Y. Thurner, J. Vac. Sci. Technol. A 10, 3266 (1992).

${ }^{11}$ S. H. Baker, S. C. Thornton, A. M. Keen, T. I. Preston, C. Norris, K. W. Edmonds, and C. Binns, Rev. Sci. Instrum. 68, 1853 (1997).

${ }^{12}$ S. H. Baker, S. C. Thornton, K. W. Edmonds, M. J. Maher, C. Norris, and C. Binns, Rev. Sci. Instrum. 71, 3178 (2000).

${ }^{13}$ B. D. Cullity and S. R. Stock, Elements of X-ray Diffraction, 3rd ed. (Prentice-Hall, Upper Saddle River, NJ, 2001), p. 351.

${ }^{14}$ J. Li, Z. L. Wang, H. Zeng, S. Sun, and J. P. Liu, Appl. Phys. Lett. 82, 3743 (2003).

${ }^{15}$ Smithells Metals Reference Book, edited by Eric A. Brandes (Butterworths, Boston, 1983), p. 13-45.

${ }^{16}$ E. C. Stoner and E. P. Wohlfarth, Philos. Trans. R. Soc. London, Ser. A 